\title{
PENGARUH RANGSANGAN PERMAINAN LOGIKA SEBELUM TANDING TERHADAP PENERAPAN DAN PENGEMBANGAN TAKTIK PERMAINAN BOLA BASKET PADA TIM UKM BOLA BASKET FAKULTAS KEDOKTERAN UNPAD
}

\author{
Razif Fiil Ikhlas ${ }^{1}$, Vita M. T. Lubis ${ }^{2}$, Vitriana ${ }^{3}$
}

${ }^{1}$ Fakultas Kedokteran, Universitas Padjadjaran, Bandung, Indonesia,

${ }^{2}$ Divisi Fisilogi, Fakultas Kedokteran, Universitas Padjadjaran, Bandung, Indonesia,

${ }^{3}$ Departemen Ilmu Kedokteran Fisik dan Rehabilitasi, RSUP Dr.

Hasan Sadikin, Bandung, Indonesia.

\begin{abstract}
Logic is subset of philosophy that studies reasoning. This function is done by the prefrontal region. The purpose of this study is to know the effects of logical stimulation before match to the tactical application at the Basketball club in Faculty of Medicine, University of Padjadjaran. The study showed that the group that was given stimulation of logical games has a significantly higher mean $(p<0.05)$. The conclusion of this study is logical stimulation can increase the capability of Basketball club, Faculty of Medicine, Universitas Padjadjaran.

Keywords: cognitive, logical stimulation, tactic
\end{abstract}

Korespondensi: Redaksi JIFO, Laboratorium Sentral, Universitas Padjadjaran, Jalan Raya Jatinangor KM. 21, Sumedang, Jawa Barat, Indonesia. E-mail: amrosdianto@gmail.com 


\section{PENDAHULUAN}

Logika merupakan bidang pengetahuan dalam lingkungan filsafat yang memelajari secara teratur azas-azas dan aturan-aturan penalaran yang benar, sebagai metode yang digunakan untuk membedakan bentuk penalaran yang benar dan penalaran yang salah. ${ }^{1,2}$ Berbagai penelitian dilakukan untuk menilai pengaruh logika terhadap fungsi kognisi otak dalam meningkatkan performa para atlet. ${ }^{3,4,5}$

Dalam olahraga basket, faktor latihan yang rutin, mental tanding yang bagus, taktik yang hebat, dan kerja sama yang bagus dengan rekan satu tim merupakan kunci dari keberhasilan dalam meraih kemenangan. Pemberian rangsangan logika diharapkan mampu membuka imajinasi dan pola pikir para atlet sehingga mampu memunculkan gambaran-gambaran yang dapat membuat

\section{METODE}

Penelitian ini merupakan penelitian eksperimental, yaitu dengan memberikan suatu intervensi berupa rangsangan permainan logika pada subjek untuk melihat adanya hubungan sebabakibat terhadap penerapan dan pengembangan taktik pada permainan bola basket. Sampel dalam penelitian ini dipilih dengan metode total sampling, dengan populasi berupa semua pemain bola basket dari tim UKM Bola Basket Fakultas Kedokteran Universitas Padjadjaran.

Subjek penelitian adalah anggota Tim UKM Bola Basket FK UNPAD dengan kriteria inklusi berupa pernah latihan basket atau aktif latihan dalam UKM atau klub basket sebelumnya, pemain laki-laki tim UKM Bola Basket FK UNPAD, dan kriteria eksklusi adalah mahasiswa tingkat 4 , mengalami cedera, penyakit berat, dan gangguan penglihatan berat. Kemudian secara acak tim akan

\section{HASIL}

Pada penelitian eksperimental ini didapatkan 24 orang yang memenuhi kriteria seleksi. Subjek penelitian kemudian dibagi menjadi dua kelompok, yaitu kelompok 1 (13 orang) yang tidak diberi rangsangan logika dan kelompok 2 mereka lebih kreatif dalam membangun permainan mereka. ${ }^{6,7}$

Tim UKM Bola Basket FK UNPAD merupakan Unit Kegiatan Mahasiswa Fakultas Kedokteran Universitas Padjadjaran yang beranggotakan para mahasiswa yang memiliki kemampuan untuk bermain bola basket dengan baik. Namun sayangnya selama UKM ini berdiri belum pernah menjuarai gelar apapun dalam kompetisi basket yang telah diikuti, baik dalam skala universitas maupun antara universitas yang diselenggarakan tiap tahun.

Penelitian ini dilakukan untuk mengetahui pengaruh rangsangan permainan logika sebelum pertandingan terhadap penerapan dan pengembangan taktik permainan bola basket pada tim UKM Bola Basket FK UNPAD.

dibagi menjadi dua kelompok berdasarkan posisi dan penilaian yang dilakukan kepada pemain yang dinilai berdasarkan suatu pertandingan uji coba/ tim 1 merupakan tim yang tidak akan diberikan rangsangan logika sedangkan tim 2 akan diberikan rangsangan logika.

Penelitian dilakukan pada bulan November 2012 dengan melakukan tiga kali pengambilan dara yang terdiri dari empat sesi penilaian. Subjek penelitian diminta mengisi kuesioner yang dibuat dengan bekerja sama dengan beberapa pihak. Selain itu dilakukan penilaian oleh tim penilai yang merupakan orang yang sudah memiliki sertifikat untuk melakukan pelatihan permainan bola basket dengan akreditasi A.

Seluruh data penelitian yang diperoleh dianalisis secara statistik menggunakan SPSS for Windows dengan metode uji T-berpasangan.

(11 orang) yang diberi rangsangan. Saat proses pengambilan data, satu orang dari kelompok 1 dan dua orang dari kelompok 2 tidak hadir sehingga data tidak lengkap.

Berdasarkan Tabel 1, terjadi penurunan rerata terhadap pencapaian skor 
dari semua aspek penilaian untuk kelompok 1. Dilihat dari distribusi rerata skor, semua aspek pada tiap kali pengambilan data berada dalam rentang nilai 60-69, yaitu kategori D (kurang bagus).

Dari Tabel 2, dapat dilihat bahwa terjadi peningkatan rerata dari semua aspek pada subjek kelompok 2. Rerata dari smeua aspek pada penilaian pertama berada dalam kategori D (kurang bagus), sedangkan rerata pada penilaian kedua, ketiga, dan keempat berada dalam kategori $\mathrm{C}$ (cukup bagus).

Dari tabel 3 dapat dilihat bahwa aspek yang mengalami penurunan skor paling besar dengan membandingkan penilaian sesi pertama dan penilaian sesi keempat adalah aspek blocking. Berdasarkan tabel 4 dapat dilihat bahwa asplem yang mengalami peningkatan paling besar dengan membandingkan penilaian sesi pertama dan sesi keempat adalah aspek passing.

Berdasarkan tabel 5, dapat dilihat bahwa terjadi penurunan rerata skor dari semua aspek pada kelompok 1. Rerata semua aspek pada penilaian pertama dan kedua adalah 72.22 dan 70, yang termasuk dalam kategori C (cukup bagus). Rerata skor aspek pada penilaian ketiga dan keempat adalah 65 dan 63, yaitu kategori D (kurang bagus). Pada penilaian awal, aspek dengan nilai paling tinggi adalah aspek self efficacy and regulated dengan rerata skor 83, sedangkan aspek dengan skor paling rendah adalah aspek passing dengan rerata 63.

Berdasarkan tabel 6 dapat dillihat bahwa terjadi peningkatan skor dari semua aspek pada kelompok 2, kecuali aspek positioning. Rerata semua skor dari semua aspek di keempat sesi penilaian berada pada rentang 70-79 yaitu kategori C (cukup bagus). Rerata skor pada penilaian pertama yang paling tinggi adalah aspek self efficacy and regulated dengan skor 84 , sedangkan rerata skor paling rendah adalah aspek passing dan positioning dengan skor 64.

Tabel 1. Rerata nilai subjek kelompok 1

\begin{tabular}{lcccc}
\hline \multirow{2}{*}{ Item } & \multicolumn{4}{c}{ Rerata } \\
\cline { 2 - 5 } & $\overline{\mathrm{x}}_{1}$ & $\overline{\mathrm{x}}_{2}$ & $\overline{\mathrm{x}}_{3}$ & $\overline{\mathrm{x}}_{4}$ \\
\hline Passing & 65,89 & 63,56 & 61,89 & 60,22 \\
Positioning & 67,44 & 65,56 & 63,67 & 62,44 \\
Stealing & 67,11 & 65,67 & 64,44 & 63,56 \\
Blocking & 65,00 & 63,22 & 61,78 & 60,00 \\
Decision & 68,11 & 65,44 & 63,67 & 62,78 \\
Team work & 69,11 & 67,56 & 65,44 & 64,11 \\
Vision & 67,33 & 65,44 & 63,78 & 62,33 \\
Fleeing & 66,33 & 64,89 & 63,11 & 61,00 \\
\hline$\overline{\mathrm{x}}_{\text {total }}$ & 67,04 & 65,16 & 63,47 & 62,06 \\
\hline
\end{tabular}

Tabel 2. Rerata nilai subjek kelompok 2

\begin{tabular}{lcccc}
\hline \multirow{2}{*}{ Item } & \multicolumn{4}{c}{ Rerata } \\
\cline { 2 - 5 } & $\overline{\mathrm{x}}_{1}$ & $\overline{\mathrm{X}}_{2}$ & $\overline{\mathrm{x}}_{3}$ & $\overline{\mathrm{x}}_{4}$ \\
\hline Passing & 67,22 & 69,78 & 72,00 & 74,33 \\
Positioning & 66,56 & 69,44 & 71,78 & 73,11 \\
Stealing & 66,56 & 67,89 & 69,89 & 71,11 \\
Blocking & 67,56 & 69,78 & 71,89 & 74,11 \\
Decision & 66,11 & 68,89 & 68,89 & 74,78 \\
Team work & 68,56 & 70,56 & 74,00 & 75,44 \\
Vision & 68,22 & 71,11 & 73,78 & 75,89 \\
Fleeing & 67,11 & 69,89 & 71,56 & 73,67 \\
\hline$\overline{\mathrm{x}}_{\text {total }}$ & 67,24 & 69,54 & 71,72 & 74,06 \\
\hline
\end{tabular}


Tabel 3. Perkembangan penilaian subjek kelompok 1

\begin{tabular}{lc|ccc}
\hline \multirow{2}{*}{ Item } & $\overline{\mathrm{x}}_{\mathbf{1}}-\overline{\mathrm{x}}_{\mathbf{4}}$ & \multicolumn{3}{|c}{$\overline{\mathrm{x}}_{\mathbf{1}} / \overline{\mathrm{x}}_{4}$} \\
\cline { 3 - 5 } & & $\mathbf{S D}$ & $\mathbf{T}$ & Nilai p \\
\hline Passing & 5,667 & 2,179 & 7,800 & 0,000 \\
Positioning & 5,000 & 1,414 & 10,607 & 0,000 \\
Stealing & 5,333 & 2,872 & 5,570 & 0,001 \\
Blocking & 5,000 & 2,915 & 5,145 & 0,001 \\
Decision & 5,000 & 1,414 & 10,607 & 0,000 \\
Team work & 3,556 & 1,878 & 5,679 & 0,000 \\
Vision & 5,000 & 0,866 & 17,321 & 0,000 \\
Fleeing & 5,333 & 2,000 & 8,000 & 0,000 \\
\hline
\end{tabular}

$\mathrm{SD}=$ standard deviasi; $\overline{\mathrm{x}}_{1}=$ rerata penilaian pertama; $\overline{\mathrm{x}}_{4}=$ rerata penilaian keempat

Tabel 4. Perkembangan penilaian subjek kelompok 2

\begin{tabular}{lc|ccc}
\hline \multirow{2}{*}{ Item } & \multirow{2}{*}{$\overline{\mathrm{x}}_{\mathbf{1}}-\overline{\mathrm{x}}_{\mathbf{4}}$} & \multicolumn{3}{|c}{$\overline{\mathrm{x}}_{\mathbf{1}} / \overline{\mathrm{x}}_{\mathbf{4}}$} \\
\cline { 3 - 5 } & & SD & $\mathbf{T}$ & Nilai $\mathbf{p}$ \\
\hline Passing & $-7,111$ & 3,180 & $-4,600$ & 0,000 \\
Positioning & $-6,556$ & 3,395 & $-5,792$ & 0,000 \\
Stealing & $-4,556$ & 2,351 & $-5,813$ & 0,000 \\
Blocking & $-6,556$ & 3,358 & $-5,856$ & 0,000 \\
Decision & $-8,667$ & 3,279 & $-7,930$ & 0,000 \\
Team work & $-6,889$ & 1,167 & $-17,714$ & 0,000 \\
Vision & $-7,667$ & 2,739 & $-8,398$ & 0,000 \\
Fleeing & $-6,556$ & 1,878 & $-10,471$ & 0,000 \\
\hline
\end{tabular}

$\mathrm{SD}=$ standard deviasi; $\overline{\mathrm{x}}_{1}=$ rerata penilaian pertama; $\overline{\mathrm{x}}_{4}=$ rerata penilaian keempat

Tabel 5. Rerata skor penilaian aspek tim kelompok 1

\begin{tabular}{lcccc}
\hline \multirow{2}{*}{ Item } & \multicolumn{4}{c}{ Rerata } \\
\cline { 2 - 5 } & $\overline{\mathrm{x}}_{1}$ & $\overline{\mathrm{x}}_{2}$ & $\overline{\mathrm{x}}_{3}$ & $\overline{\mathrm{x}}_{4}$ \\
\hline Menyerang & 72 & 70 & 68 & 67 \\
Bertahan & 71 & 68 & 60 & 57 \\
Built up play & 71 & 69 & 63 & 60 \\
Passing & 66 & 63 & 62 & 61 \\
Positioning & 68 & 66 & 64 & 63 \\
Pressing & 69 & 66 & 57 & 55 \\
Marking & 68 & 65 & 56 & 54 \\
Self efficacy and regulated & 83 & 83 & 76 & 75 \\
Creativity & 82 & 81 & 77 & 75 \\
\hline$\overline{\mathrm{x}}_{\text {total }}$ & 72,22 & 70 & 64,78 & 63 \\
\hline
\end{tabular}

$\overline{\mathrm{X}}_{1}=$ rerata penilaian pertama; $\overline{\mathrm{X}}_{2}=$ rerata penilaian kedua; $\overline{\mathrm{X}}_{3}=$ rerata penilaian ketiga;

$\overline{\mathrm{x}}_{4}=$ rerata penilaian keempat

\section{DISKUSI}

Hasil uji statistik menunjukkan pemberian rangsangan permainan logika sebelum bertanding mampu meningkatkan dan mengembangkan taktik permainan basket secara bermakna. Hasil rerata 17 skor yang terdiri dari 8 aspek penilaian pribadi dan 9 aspek penilaian tim yang dinilai pada kedua kelompok menunjukkan bahwa skor yang diperoleh kelompok 2 memiliki rerata yang lebih tinggi dibandingkan dengan rerata kelompok 1.
Hasil uji t-berpasangan menunjukkan bahwa skor untuk kelompok 2 lebih tinggi secara bermakna dibandingkan dengan kelompok 1 , dengan nilai $\mathrm{p}<0,05$. Hal ini mendukung teori-teori yang telah ada sebelumnya bahwa pemberian rangsangan aspek kognitif mampu meningkatkan performa para atlet. Meski pada aspek positioning terjadi peningkatan yang tidak signifikan dengan nilai $\mathrm{p}=0,073$, aspek ini tetap mengalami 
peningkatan pada skor penilaian sebelumnya dengan sangat signifikan. Peneliti mengasumsikan hal ini disebabkan pemain yang diberikan rangsanagan logika mencapai nilai ambang atau threshold kemampuan kognitifnya terhadap aspek yag dirangsang sehingga peningkatannya tidak signifikan. Ambang ini ditentukan oleh faktor-faktor yang memengaruhi proses kognitifnya, yang terdiri dari cognitive resource, potential cognitive, attention, memory, cognitive inhibition, dan executive function. ${ }^{8}$

Cognitive resource memengaruhi kecepatan dan kapasitasnya dalam mengolah dan menyimpan informasi yang diterima dan menjadikannya experience untuk dijadikan patokan dalam masalah berikutnya. ${ }^{8,9}$ Attention merupakan suatu prose yang menentukan kadar informasi yang diterima selagi orang itu masih sadar dalam menangkap makna dar informasi yang diterima baik itu informasi yang sederhana maupun kompleks. Faktor ini dapat membuat individu mampu memerhatikan hal-hal kecil dan tersirat agar mampu menangkap makna secara utuh dari informasi yang ada. ${ }^{10,11}$ Potential cognitive berperan dalam memcahkan masalah dengan cepat dan tanggap karena faktor ini menentukan kualitas dari fungsi kognitif individu untuk dapat mengingat kembali terhadap pengalaman-pengalaman yang ada dari semua ilmu dan teori yang telah didapat. ${ }^{12}$

Cognitive inhibition merupakan faktor yang mengatur keefektifan dan fleksibilitas dari fungsi otak manusia dengan cara mengontrol proses attention, mengurangi pemikiran-pemikiran yang mengganggu, mengontrol aksi motoric, dan membantu dalam pertikaran dan memilih pemikiran yang sama-sama penting. ${ }^{13,14}$ Executive functioning yang berperan dalam pengambilan keputusan dan berpikir secara kritis dan kreatif. ${ }^{10,15}$

Asumsi lain dari penyebab hasil tersebut adalah 5 dari 9 pemain dari kelompok 2 yang datang sewaktu

\section{SIMPULAN}

Berdasarkan penelitian yang telah dilakukan, dapat disimpulkan bahwa:

1) Pemberian rangsangan permainna logika sebelum bertanding mampu pengambilan data keempat mengisi kuesioner bahwa mereka sedang dalam kondisi kelelahan sehingga mereka tidak terlalu aktif dalam mencari posisi. Selain itu, dari catatan yang ditinggalkan tim penilai pada lembaran penilaian tertulis bahwa 4 dari 9 pemain kelompok 2 tidak terlalu aktif ketika dimainkan mencari posisi, untuk penururnan pad akelompok 1 , peneliti berasumsi bahwa itu akibat permainannya tertekan oleh peningkatan performa kelompok 2. Menurut Glaze, hal ini disebabkan kegagalan tim dalam membentuk permainan tim, kehilangan fokus terhadap tujuan dan memanfaatkan sumber daya yang ada, kegagalan dalam mengapresiasikan kemampuan dan berbagi aktivitas, kehilangan motivasi dalam diri, dan gagal dalam mengeluarkan motibasi untuk mendorong diri dan rekan untuk maju dalam mencapai tujuan, dan gagal untuk berusaha menampilkan permainan yang seharusnya serta beradaptasi dalam menjalankan tugasnya saat mendapat masalah. $^{16}$

Asumsi lain adalah pemain akan mengalami kesulitan dalam melakukan penampilan yang maksimal disebabkan berada dalam situasi yang sulit untuk mereka tangani dengan kemampuan yang dimiliki, berusaha dalam memperbaiki permasalahan akibat kesalahan yang timbul dan diperbuat, membutuhkan kemampuan dalam mengatasi masalah yang memnutuhkan respons yang lebih, dan respons yang diberikan tidak terlatih dengan baik untuk menyelesaikan permasalahan yang ada. ${ }^{17}$

Keterbatasan penelitian ini ada pada aspek-aspek yang diteliti akibat keterbatasan kemampuan peneliti dalam membuat dan mengembangkan kuesioner, serta terbatasnya subjek penelitian pada pemain basket pria, sheingga belum dapat diketahui pengaruh jenis kelamin terhadap penerapan dan pengembangan taktik permainan basket setelah diberikan rangsangan permainan logika.

meningkatkan penerapan dan pengembangan taktik permainan bola basket pada tim UKM Bola Basket FK UNPAD. 
2) Pemberian rangsangan permainan logika mampu meningkatkan kreativitas dan critical thinking tim
UKM Bola Basket FK UNPAD dalam bermain bola basket.

\section{DAFTAR PUSTAKA}

1. Gie L. Suatu konsep ke arah penertiban bidang filsafat. Trans Mudgorfir A. Karya Kencana, Yogyakarta; 1997.

2. Copi MI. Introduction to logics. Edisi ke-5; Macmillan Publisihing Co, New York; 1978.

3. Boutcher SH, Crews DJ. The effect of a pre-shot attentional routine on a well-learned skill. International Journal of Sport Pcyshology. 1987;18:30-9.

4. Currie G, Ravenscroft I. Mental stimulation and motor imagery. Philosophy of Science. 1997;64:16180.

5. Kavussanu M, Crews DJ, Gill DL. The effects of single versus multiple measures of biofeedback on basketball free throw shooting performance. International Journal of Sport Psychology. 1998;29(2);13244.

6. Moran AP. Sport and exercise psychology: A critical introduction. Routledge; 2004.

7. Thelma SH. Advances in sport psychology. Edisi ke-3: Human Kinetics; 2008.

8. Kail R. Speed of information processing: Developmental change and links to intelligence. Journal of School Psychology. 2000;38:51-62.

9. Hale S. A global developmental trend in cognitive processing speed: Domain specificity and stability during childhood and adolescence. Journal of Cognition and Development. 2006;7:119-37.
10. Santrock WJ. Adolescence. Edisi ke12: McGraw Hill, New York; 2008.

11. Klimkeit EI, Mattingley JB, Sheppard DM, Farrow M, Bradshaw JL. Examining the development of attention and executive functions in children with a novel paradigm. Child Neuropsychology. 2004;10:201-11.

12. Labouvie-Gief G. Emerging structures of adult thought. Dalam: Arnet JJ dan Tanner JL, editor. Emerging Adults in America. American Psychological Education. Washington, DC; 2006.

13. Anderson VA, Anderson P, Northan E, Jacobs R, Catroppa C. Development of executive functions through late childhood and adolescence in an Australian Sample. Developmental Neuropsychology. 2003; 20: 385-406.

14. Munakata Y. Information processing approaches to development. Dalam: Damon W dan Lerner R, editor. Handbook of Child Psychology, Edisi ke-2; 2006.

15. Baddeley AD. Working memory, thought, and action. Oxford University Press; 2007.

16. Gaze S. Team development and the five traits of great teams. Tersedia dari:

www.greatresultsteambuilding.net.

17. Scott WD, Beevers CG, Mermelstein RJ. Depression vulnerable and nonvulnerable smokers after a failure experience: Examining cognitive selfregulation and motivation. Behavior Modification. 2008;32:519-39. 